\title{
Modification of the Titanium Oxide Morphology and Composition by a Combined Chemical-electrochemical Treatment on cp Ti
}

\author{
Ernesto Peláez-Abellán, Laís Tereza Duarte, Sonia Regina Biaggio*, \\ Romeu Cardozo Rocha-Filho, Nerilso Bocchi \\ Departamento de Química, Universidade Federal de São Carlos - UFSCar, \\ CP 676, CEP 13560-970, São Carlos, SP, Brazil
}

Received: September 30, 2011; Revised: November 16, 2011

\begin{abstract}
A combined chemical-electrochemical oxidation method to obtain porous bioactive $\mathrm{TiO}_{2}$ films on titanium is reported. In this case, a titanium chemical pre-etching followed by the micro-arc oxidation (MAO) treatment is proposed and optimized, to obtain a high-roughness and porous surface which benefits the titanium/bone integration. The MAO treatment at various rates (different current densities) allowed to define the influence of the oxide growth rate on the surface morphology and to design the best features for each case. Titanium samples were pre-etched using a $2 \% \mathrm{HF}$ solution as a function of the etching time, and then anodized by the MAO treatment in a $0.5 \mathrm{M} \mathrm{H}_{3} \mathrm{PO}_{4}$ solution at current densities in the 10 to $90 \mathrm{~mA} \cdot \mathrm{cm}^{-2}$ range. High porosity ( 0.5 to $1 \mu \mathrm{m}$-diameter pores) and higher phosphorous content for $\mathrm{TiO}_{2}$ films were achieved by first etching the Ti sample for 180 seconds in the HF solution, and then applying current densities in the 80 to $90 \mathrm{~mA} \cdot \mathrm{cm}^{-2}$ range for the micro-arc oxidation process.
\end{abstract}

Keywords: titanium anodization, anodic oxide films, micro-arc oxidation, porous titanium oxide, titanium oxide roughness

\section{Introduction}

Titanium oxide films have attracted much attention due to their potential applications in catalysts, sensors, solar cells, microelectronic devices, and microwave communication systems. These films present a high mechanical strength and stable dielectric properties characterized by a high relative dielectric constant and low dielectric loss ${ }^{1}$. The use of $\mathrm{TiO}_{2}$ films has been extended to medical applications as a bioactive surface of orthopedic or dental implants ${ }^{2-7}$.

Titanium and its alloys have been widely used as loadbearing implants. However, they exhibit poor osteoinductive properties. To improve their bioactivity, bioactive coatings of $\mathrm{TiO}$, have been prepared on their surfaces by various surfacemodifying techniques, e.g. plasma spraying, sol-gel method, electrochemical deposition, pulsed-laser deposition, filtered-arc deposition, and reactive-sputtering methods. The use of micro-arc discharge oxidation (MAO) has also been proposed to produce ceramic coatings on titanium substrates $^{8-13}$. By applying discharges at high voltages, porous $\mathrm{TiO}_{2}$ films, including the three polymorphic forms rutile, anatase, and brookite, can be formed on titanium and its alloys ${ }^{14}$. MAO coatings on the titanium surface are effective as a chemical barrier against the release of metal ions from the substrate and can enhance the corrosion resistance of the material.

Surface properties of the $\mathrm{TiO}_{2}$ anodic films are sensitive to the oxide growth conditions ${ }^{15-17}$. The electrochemical growth behavior depends on the particular electrolyte used and, for a given electrolyte, on the values of the applied

*e-mail: biaggio@ufscar.br current density (or the growth rate), electrolyte concentration and temperature, electrolyte stirring rate, and cathode-toanode surface area ratio.

Titania-based coatings on $\mathrm{Ti}$ and its alloys have been obtained by MAO in electrolytes containing $\mathrm{Ca}$ and $\mathrm{P}^{18-21}$. The thus-modified surfaces can potentially be used as hardtissue replacement materials due to the incorporation of $\mathrm{Ca}$ and $\mathrm{P}$. In fact, MAO coatings may have specific surface structures such as amorphous phase, non-equilibrium solids and mixed compounds, since complex plasma reactions, such as ionization and plasma condensation, may occur at the electrode surface during the oxide growth ${ }^{8}$. All these aspects certainly change the morphological and the corrosion properties of the oxide film protecting the biomaterial.

Titanium is par excellence the material used as orthopedic and dental implant in the human body; however, it is bioinert by nature. For this reason, investigations with the purpose of modifying its surface in order to turn it bioactive have been frequently reported in the literature. In the present work, we report on a combined chemical-electrochemical oxidation method to obtain porous $\mathrm{TiO}_{2}$ films on titanium. In this case, a combination of a chemical pre-etching followed by the MAO treatment is proposed and optimized. The focus is to remove the initial oxide formed during the preparation of the Ti sample, which does not present the best properties to develop a bone/implant integration. On the other hand, a high surface roughness and porosity, obtained by the micro-arc oxidation process, also benefits the anchorage of bone. The MAO treatment in galvanostatic conditions at 
various rates (different current densities) allows to define the influence of the oxide growth rate on the surface morphology and to design the best features for each case. Therefore, the roughness parameters, the pore configuration and the phosphorous incorporation of the as-obtained $\mathrm{TiO}_{2}$ films are analyzed as a function of the oxide growth conditions.

\section{Experimental}

Pieces of cp Ti $(10 \times 10 \times 0.4 \mathrm{~mm})$ were used as samples. Their surfaces were ground to 400 grits using a silicon carbide paper, followed by cleaning with distilled water in an ultrasonic bath. Then they were etched using a $2 \% \mathrm{HF}$ acid solution during a given time in the 30 to 180 seconds range in order to renew the surface, followed by rinsing with distilled water and air-drying prior to the MAO treatment.

The micro-arc oxidation setup consisted of a homemade high-voltage power supply, an electrochemical glass cell, a magnetic stirrer, and a cooling system to mantain the electrolyte temperature at $25{ }^{\circ} \mathrm{C}$. The electrochemical glass cell contained a $0.5 \mathrm{M} \mathrm{H}_{3} \mathrm{PO}_{4}$ aqueous solution as electrolyte, a Ti sample as anode, and a Ti plate as cathode. The anodic current densities were set in the range 10-90 mA. $\mathrm{cm}^{-2}$. The processing time for each sample anodization varied from 2 minutes (at higher currents) to 10 minutes (at lower currents), depending on the time needed to reach the sparking conditions, i.e. the cell voltage oscillations.
The morphology of the oxide films was observed by scanning electron microscopy (SEM) using a Phillips XL 30 TMP microscope. In addition, the elemental analysis of the surfaces was done by energy dispersive X-ray spectroscopy (EDS).

The microroughness after both etching and MAO treatments was assessed with Rank Taylor-Hubson profilometers (models Talysurf 10 and Surtronic 3). This was carried out using the stylus method, which works on a principle similar to a household record player. The equipments were found to give very reliable data: the maximum vertical and horizontal resolutions were, respectively, $0.01 \mu \mathrm{m}$ and $0.005 \mathrm{~mm}$ for the Surtronic-3 model, and $0.2 \mu \mathrm{m}$ and $0.05 \mathrm{~mm}$ for the Talysurf-10 model.

\section{Results and Discussion}

\subsection{Morphology and roughness of the titanium surface after the etching treatment}

A previous etching step in a $2 \% \mathrm{HF}$ aqueous solution was proposed in order to remove the native oxide grown in air during the titanium handling process and to provide a reproducible surface for the subsequent micro-arc oxidation process. Figure 1 displays SEM micrographs of the Ti surface as a function of the etching time, i.e. 30, 60, 120 and 180 seconds, where different surface aspects for

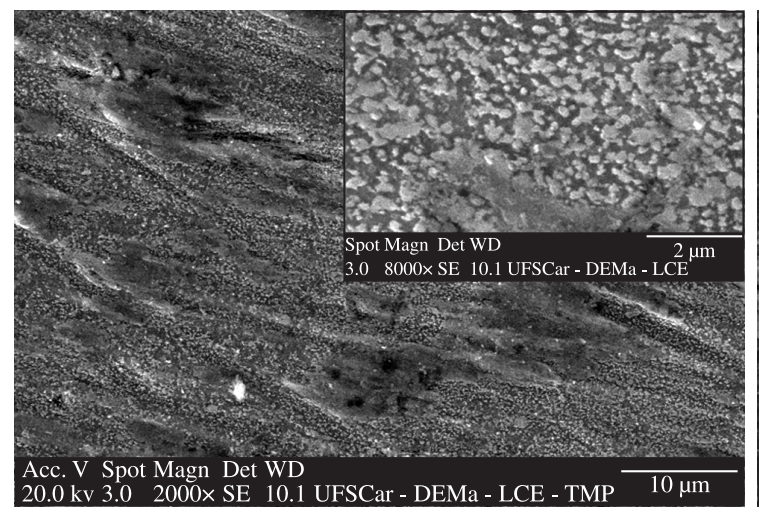

(a)

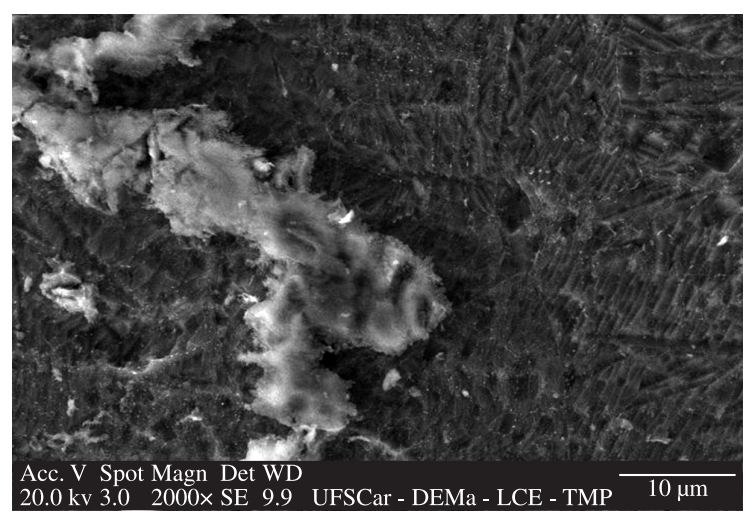

(c)

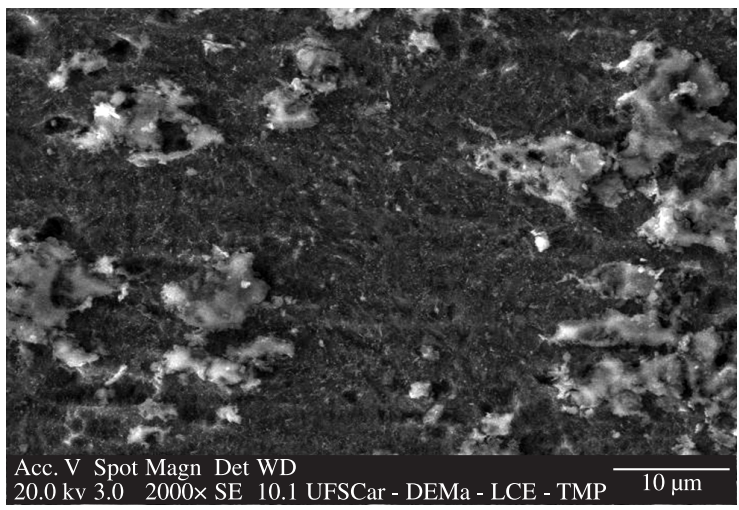

(b)

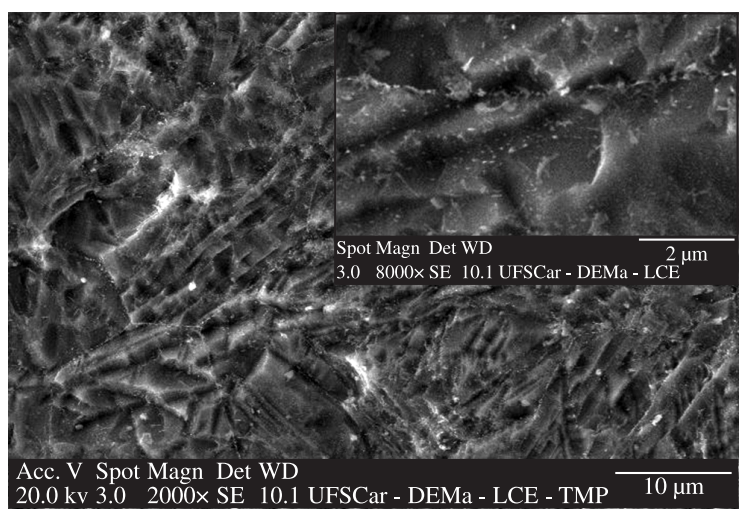

(d)

Figure 1. SEM micrographs of Ti surfaces etched in a $2 \%$ HF solution at different etching times: a) 30 seconds; b) 60 seconds; c) 120 seconds; and d) 180 seconds. Magnifications: 2000 and $8000 \times$ (inset). 
each sample can be seen. The oxide outer layer dissolution was higher for increasing etching times, revealing a new Ti surface characterized by grooves and ridges oriented in the direction of the previous grinding; the light-gray parts on the surface at lower etching times indicate the remaining undissolved outer layer. For the sample etched during 180 seconds the outer layer was completely removed, indicating that the longest etching promoted the formation of a new and rough Ti surface.

EDS analyses were done for all samples after the etching treatment. The composition of the modified surface was about $100 \% \mathrm{Ti}$ (within the experimental error) for the 30, 60 and 120 seconds etching times. However, the composition changed dramatically for the surface etched during 180 seconds, including a significant amount of fluorine: $37 \% \mathrm{Ti} ; 48 \% \mathrm{O} ; 15 \% \mathrm{~F}$. This result suggests that

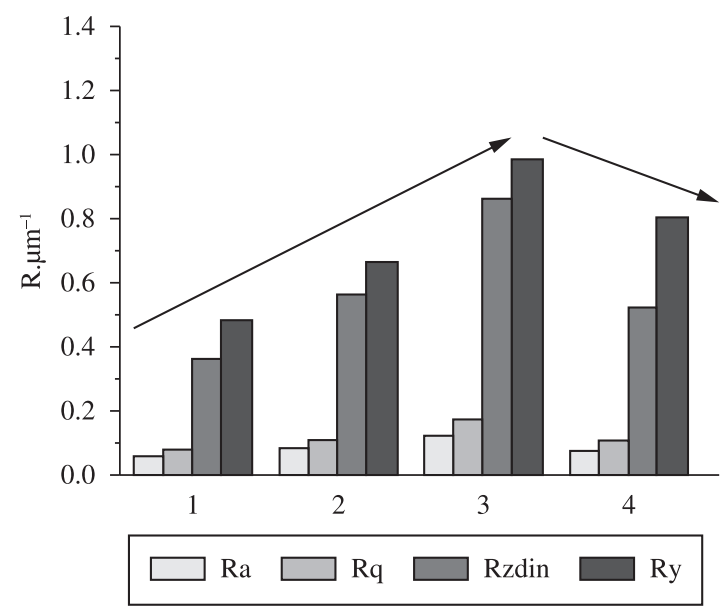

Figure 2. Roughness parameters of Ti surfaces etched in a $2 \% \mathrm{HF}$ solution at different etching times: 1) 30 seconds; 2) 60 seconds; 3) 120 seconds; and 4) 180 seconds - see text.

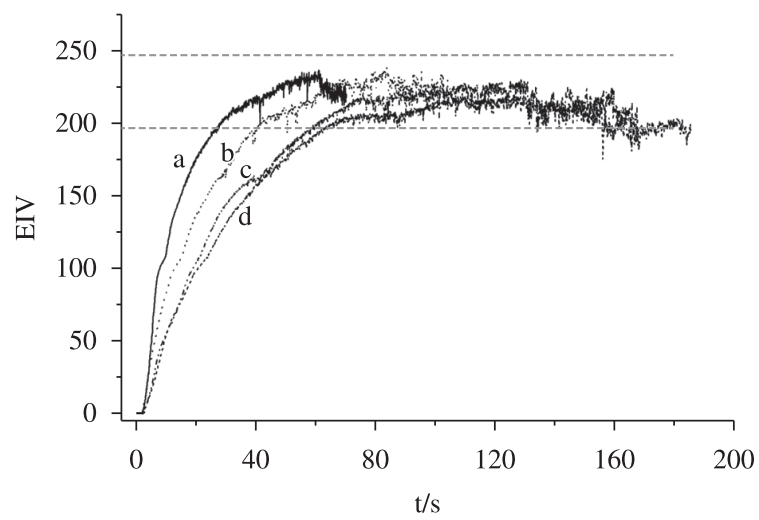
(a) $90 \mathrm{~mA} \cdot \mathrm{cm}^{-2}$
(b) $70 \mathrm{~mA} \cdot \mathrm{cm}^{-2}$
(c) $50 \mathrm{~mA} \cdot \mathrm{cm}^{-2}$
(d) $40 \mathrm{~mA} \cdot \mathrm{cm}^{-2}$

(a) the totally renewed Ti surface was promptly activated in air to form a new film constituted by titanium oxide and fluoride ions, the latter either adsorbed at the metal/oxide interface or incorporated into the oxide film.

Eventually, variations on the surface roughness after the etching were consistent with the changes observed in the SEM micrographs of the etched specimens. The roughness parameters, shown in Figure 2, are expressed in terms of $R_{\mathrm{a}}, R_{\mathrm{q}}, R_{\mathrm{z}}(\operatorname{din})$ and $R_{\mathrm{y}}$ values. $R_{\mathrm{a}}$, the most used parameter of roughness, is the arithmetic mean of the departures of the profile from de surface mean line; $R_{\mathrm{q}}$ is the roughness mean square parameter corresponding to $R_{\mathrm{a}} ; R_{\mathrm{z}}(\mathrm{din})$ is the average of all the values of peak-to-valley heights in the assessment length; and $R_{\mathrm{y}}$ is the largest peak-to-valley values of the assessment.

The general trend observed in Figure 2 indicates that the Ti surface roughness significantly increased with the etching time up to 120 seconds and then somewhat decreased for 180 seconds. The initial increase of the roughness parameters, defining a roughening effect, can be interpreted as due to a gradual dissolution of the outer oxide surface layer; for 180 seconds, however, the outer layer was completely dissolved and the titanium surface activated to form a more homogeneous oxide film, changing the surface roughness to another profile value. In such case, the roughness parameter $R_{\mathrm{a}}$ for the titanium oxide surface was about $0.1 \mu \mathrm{m}$, laying within the nano and micro scale.

\subsection{Micro-arc oxidation, morphology and composition of the titanium oxide film}

Due to the fact that the old surface was completely dissolved giving rise to a new homogeneous Ti oxide surface after being etched for 180 seconds, the majority of the analyses presented thereinafter are made on this surface.

The anode-to-cathode voltage $(E)$ as a function of time during the galvanostatic anodization of titanium in a $0.5 \mathrm{M} \mathrm{H}_{3} \mathrm{PO}_{4}$ aqueous solution is presented in Figure 3. At

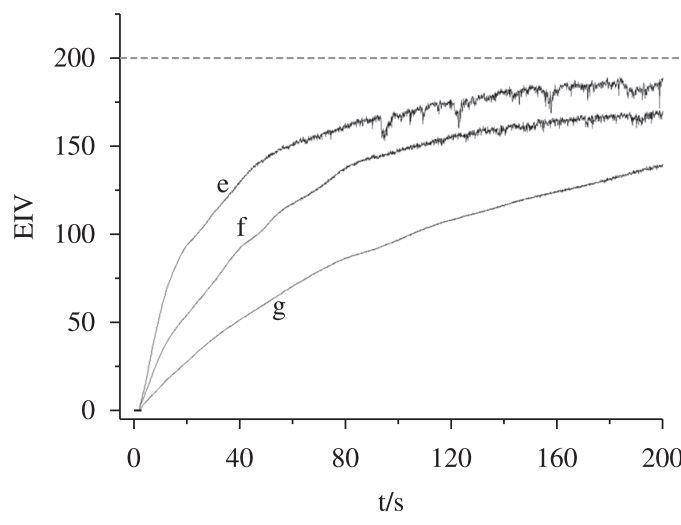

$\begin{array}{lll}\text { (e) } 30 \mathrm{~mA} \cdot \mathrm{cm}^{-2} & \text { (f) } 20 \mathrm{~mA} \cdot \mathrm{cm}^{-2} & \text { (g) } 10 \mathrm{~mA} \cdot \mathrm{cm}^{-2}\end{array}$

(b)

Figure 3. Anode-to-cathode voltage vs. time profiles during galvanostatic anodizations of Ti (previously etched in a $2 \%$ HF solution for 180 seconds) in a $0.5 \mathrm{M} \mathrm{H}_{3} \mathrm{PO}_{4}$ solution at higher (a) and lower (b) current densities. 
lower voltages, the oxide growth behavior is very stable and reproducible, presenting a linear relationship between the voltage and the growth time. Similarly to previous results on titanium anodization ${ }^{22}$, this linear behavior indicates that the increase of the oxide thickness occurs under high-field conditions.

However, considerable voltage oscillations begin to appear at higher values of voltage which characterize the breakdown phenomenon of the oxide films. Figure 3 a shows voltage surges of up to about $\pm 30 \mathrm{~V}$, which increase with the anodizing time beyond the initial breakdown voltage. As the imposed current density is increased the slope for the
E-t profile is higher, indicating that the oxide layer thickness grows faster. Then, the limiting voltage value (in the range of 200-250 V) is reached after a shorter time. For the lower current density values (Figure 3b), longer anodization times were necessary to reach the limiting voltage value and to observe the voltage oscillations. Other authors ${ }^{14,19,23}$, describing in more details the features of the MAO process for Ti under galvanostatic conditions, reported similar behavior of the voltage-time profile at the lower current densities in other electrolyte solutions.

Anodic oxides on $\mathrm{Ti}$ and its alloys grow at a rate of about 2-3 nm. $\mathrm{V}^{-1[3,22]}$, which means that the thickness of

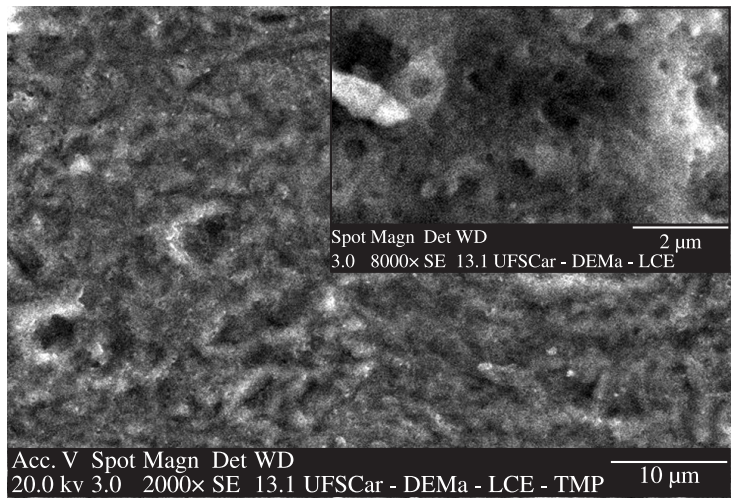

(a)

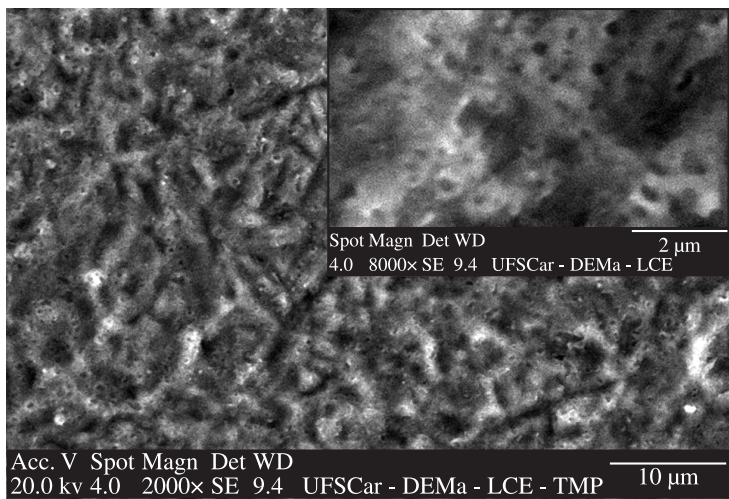

(c)

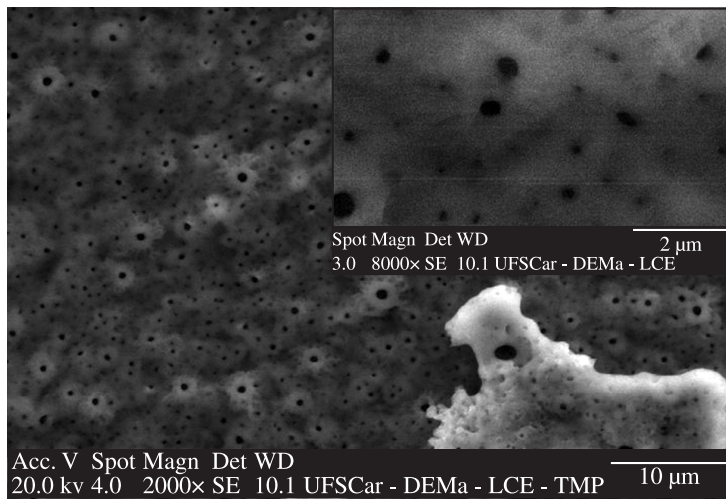

(e)

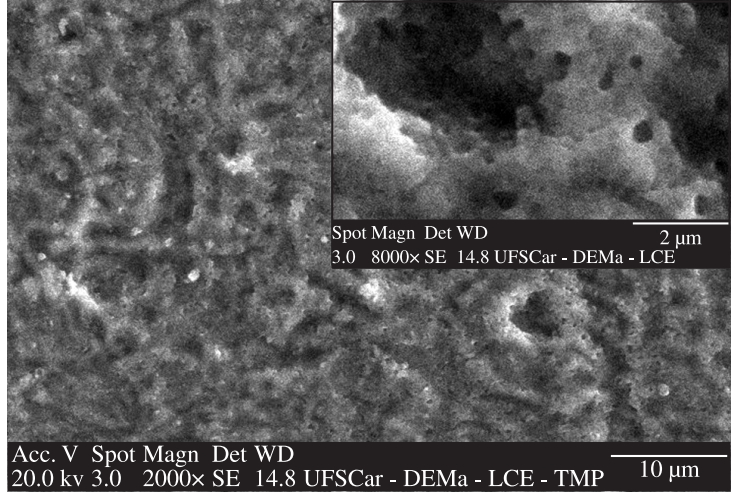

(b)

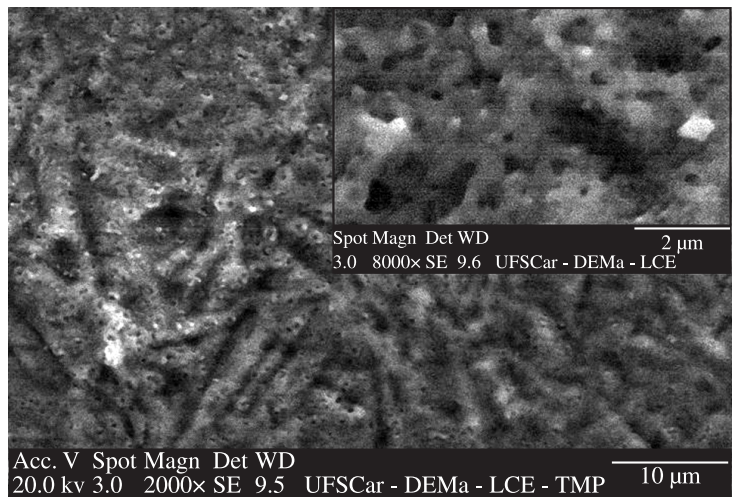

(d)

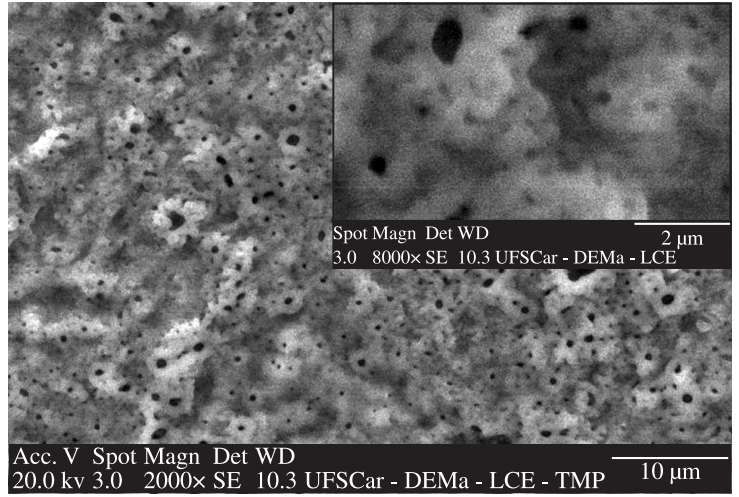

(f)

Figure 4. SEM micrographs of 180 -seconds etched Ti surfaces after the MAO treatment for 600 seconds in a $0.5 \mathrm{M} \mathrm{H}_{3} \mathrm{PO}_{4}$ solution at different current densities: a) 10; b) 30; c) 40; d) 60; e) 80; and f) $90 \mathrm{~mA} \cdot \mathrm{cm}^{-2}$. Magnifications: 2000 and 8000× (inset). 
the oxides formed under the conditions given in Figure 3 varies in the 400 to $600 \mathrm{~nm}$ range. It is already known that oxides growing under a MAO procedure do not exactly follow such anodization ratio due to numerous processes occurring at the very high voltage conditions ${ }^{8}$. However, as this deviation is observed only after the film rupture voltage, the anodization rate remains a valid approach to estimate the oxide film thickness.

In general, the anodic film morphology is critically dependent on the oxide growth behavior, especially during the micro-arc anodization. In fact, before the voltage oscillations begin, the specimens are already passivated by an oxide film that is basically a non-porous, compact, and uniform barrier-type film ${ }^{17,24}$. The plasma discharges on the samples are observed to become more intense during the MAO treatment as the current density is increased. When a micro-arc discharge extinguishes in the discharge channel, it is possible that coarse pores with large diameters remain on the coating surface. Indeed, as shown in Figure 4 for the 180 seconds-chemically etched Ti samples followed by the MAO treatment, the oxide coating exhibits a rough and porous surface formed by a dense and compact film composed by numerous micro-protrusions with pores, looking like craters on mountain elevations. These features are due to the dielectric breakdown of the oxide film that occurs particularly in the micro-arcing region. Depending on the current density employed during $\mathrm{Ti}$ anodization, different surface topographies were obtained, especially when the pore diameter is taken into account. Indeed, the micro arcing on the titanium anode surface became more active and vigorous as the voltage was increased, resulting in pores of very irregular shapes.

Figure 4 also reveals that, for the lower current density cases, the mean pore diameter was $\sim 500 \mathrm{~nm}$ (see insets), while for the higher current density cases it was $\sim 1 \mu \mathrm{m}$. For the latter, pores like a hole appear randomly distributed on the surface with a maximum diameter of several micrometers, which are most likely due to the interconnection or condensation of some pores to each other during the severe conditions of the micro-arcing process. In addition, a sphere-like pattern can also be observed for the current densities of 80 and $90 \mathrm{~mA} \cdot \mathrm{cm}^{-2}$ (Figure 4e and 4f).

Sul et al. ${ }^{14}$ found a similar surface morphology for Ti anodized in $0.1 \mathrm{M}$ acetic acid up to a voltage of about $380 \mathrm{~V}$, which is in agreement with our results. Other results from the
MAO treatment employed to modify the Ti topography, in various electrolytes other than phosphoric acid, also indicated that the oxide coatings present a rough and porous surface, with pores of 1-4 $\mu \mathrm{m}$ diameter randomly distributed on the surface ${ }^{18,19,21,23,25,26}$. The titanium oxide surfaces presented in Figure 4 are rougher, showing smaller pores whose diameters are in the order of 0.5 to $1 \mu \mathrm{m}$. The smaller diameter seems to be a result of the stability of the oxide formed in $\mathrm{H}_{3} \mathrm{PO}_{4}$ solution, whereas the higher roughness is due to the chemical pre-etching in the HF solution.

The EDS spectra of the MAO treated samples indicate that the oxide film is basically composed of titanium and oxygen, with a minor content of phosphorous incorporated from the electrolyte. The atomic percentages of these elements are presented in Table 1 for various current densities and two different etching times. Fluorine, present in the surface etched for 180 seconds, was not detected after the MAO treatment, suggesting that it was lixiviated during the anodizing process. In addition, it was found that the $\mathrm{Ti}$ and $\mathrm{O}$ amounts do not significantly change for the different current densities, but the $\mathrm{P}$ amount increases as the current density is increased. Previously, while analyzing XPS spectra, we found that phosphorous-containing species can be incorporated from the electrolyte when the Ti oxide is grown in $\mathrm{H}_{3} \mathrm{PO}_{4}$ solutions ${ }^{22,27}$. The range of the $\mathrm{P} \%$ variation is larger for the 180 seconds-etched sample, but within the experimental error the absolute values are very similar for both etching time conditions. Therefore, the main information derived from Table 1 is that more phosphorous is incorporated into the oxide film as the applied current density is increased. Furthermore, no oxide composition change was observed for the different etching times. The $\mathrm{Ti} / \mathrm{O}$ atomic ratio was always $0.3 \%$, indicating that oxygen is present as both titanium oxide and phosphate species.

\subsection{Roughness of the titanium oxide film after the micro-arc anodization}

The roughness values for the $\mathrm{Ti}$ surfaces after the MAO treatment are summarized in Figures 5 and 6 for the samples previously etched for 30 and 180 seconds, respectively. For the 30 seconds-etched surface, Figure 5 shows that the samples have different surface topographies only when the $R_{\mathrm{z}}(\mathrm{din})$ and $R_{\mathrm{y}}$ values are considered. However, the $R_{\mathrm{a}}$ and $R_{\mathrm{q}}$ values presented a random behavior

Table 1. Elemental analyses of the Ti surface after the MAO treatment as a function of the current density and etching time.

\begin{tabular}{|c|c|c|c|c|c|c|c|c|}
\hline \multirow{3}{*}{$\begin{array}{c}\text { Current } \\
\text { density } \\
\text { mA.cm }\end{array}$} & \multicolumn{8}{|c|}{ Atomic percentage } \\
\hline & \multicolumn{4}{|c|}{ 30-seconds etching } & \multicolumn{4}{|c|}{ 180-seconds etching } \\
\hline & $\mathbf{O}$ & $\mathbf{P}$ & $\mathbf{T i}$ & Ti/O & $\mathbf{O}$ & $\mathbf{P}$ & $\mathbf{T i}$ & $\mathrm{Ti} / \mathrm{O}$ \\
\hline 40 & 76 & 1.2 & 23 & 0.3 & 76 & 0.8 & 24 & 0.3 \\
\hline 50 & 75 & 1.3 & 23 & 0.3 & 77 & 1.4 & 22 & 0.3 \\
\hline 60 & 76 & 1.4 & 22 & 0.3 & 76 & 1.1 & 23 & 0.3 \\
\hline 70 & 73 & 1.8 & 25 & 0.3 & 73 & 1.4 & 26 & 0.4 \\
\hline 80 & 77 & 2.0 & 21 & 0.3 & 77 & 2.6 & 21 & 0.3 \\
\hline 85 & 76 & 2.3 & 21 & 0.3 & 76 & 1.6 & 22 & 0.3 \\
\hline 95 & 77 & 2.2 & 21 & 0.3 & 76 & 1.7 & 22 & 0.3 \\
\hline
\end{tabular}




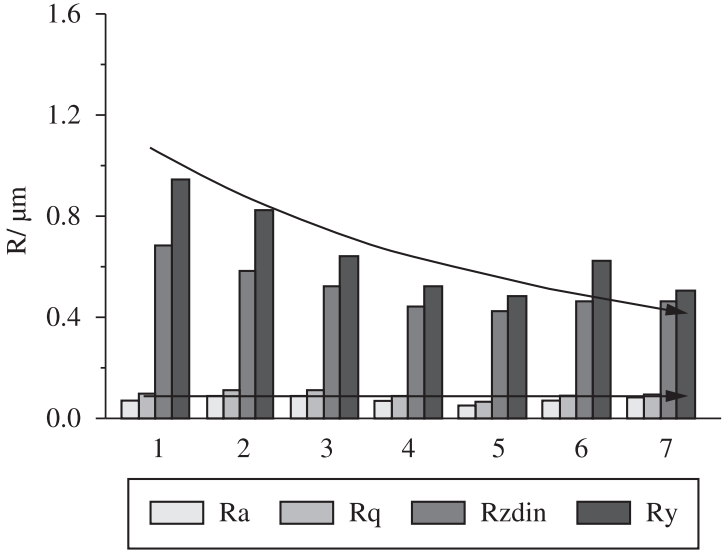

Figure 5. Roughness of 30-seconds etched Ti samples after the MAO treatment for 600 seconds in a $0.5 \mathrm{M} \mathrm{H}_{3} \mathrm{PO}_{4}$ solution at different current densities: 1) 90; 2) 85; 3) 80; 4) 70; 5) 60; 6) 50; and 7) $40 \mathrm{~mA} \cdot \mathrm{cm}^{-2}$.

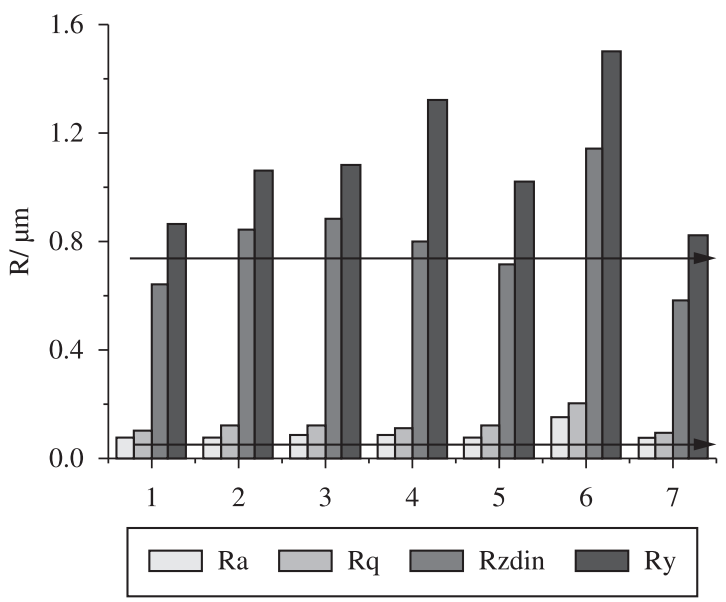

Figure 6. Roughness of 180 -seconds etched Ti samples after the MAO treatment for 600 seconds in a $0.5 \mathrm{M} \mathrm{H}_{3} \mathrm{PO}_{4}$ solution at different current densities: 1) 90;2) 85; 3) 80; 4) 70; 5) 60; 6) 50; and 7) $40 \mathrm{~mA} \cdot \mathrm{cm}^{-2}$.

for all samples. As these parameters are arithmetic mean values, they indicate that the surfaces have a similar roughness, independently of the current density used, which remains in the order of $0.1 \mu \mathrm{m}$. Aditionally, the $R_{\mathrm{z}}(\mathrm{din})$ and $R_{\mathrm{y}}$ values decreased when the current density was decreased. As these parameters refer to peak-to-valley height, their values indicate that the oxide surface is flatter when lower current densities are applied during the MAO process; in other words, the micro-protrusions with pores are higher when the current density is increased.

For the 180 seconds-etched surfaces (see Figure 6), all parameters used to express roughness presented a random behavior. In this case, the roughness induced by the
MAO coating has the same value (around $0.1 \mu \mathrm{m}$ ) as that for the 30 seconds-etched surfaces. Comparing Figsures 5 and 6 , it is clear that the influence of the chemical etching on the sample topography was more significant when the etching time was 30 seconds. This means that the Ti oxide topography is a complex property that depends not only on the applied current density during the MAO treatment, but also on other parameters like the previous etching time of the titanium sample.

\section{Conclusions}

The HF-etching process imposed to titanium previously to its anodization led to an increasing dissolution of its outer layer with etching time, so that the sample etched during 180 seconds presented a completely renewed Ti oxide surface.

During the MAO process in a $0.5 \mathrm{M}$ phosphoric acid solution for the Ti surface etched during 180 seconds, considerable voltage surges were observed beyond the oxide breakdown voltage, giving rise to a very porous oxide layer with pore diameters in the order of 0.5 to $1 \mu \mathrm{m}$. The oxide growth rate increases as the current density was increased giving rise to different oxide morphologies, especially when the pore diameters are considered. The micro-arcing on the titanium anode surface becomes more active and vigorous with increasing voltage, thus yielding oxides with irregularshaped pores.

The EDS data of the MAO treated samples revealed that the oxide film is basically composed of titanium and oxygen, with a minor content of phosphorous incorporated from the electrolyte, which became higher as the oxide growth rate (i.e. the current density) was increased. This fact is worth noticing since a higher $\mathrm{P}$ content in the $\mathrm{TiO}_{2}$ layer may improve the biomaterial osteointegration.

The obtained roughness parameters indicated that the Ti oxide topography is a complex property that may vary with the applied current density during the MAO treatment and with the previous etching time of titanium in the HF solution. Thus, it is clear that, depending on the surface requirements for the titanium oxide, at least the current density for the MAO process and the titanium surface preparation have to be controlled in order to get the desired oxide characteristics. In summary, conditions to obtain high porosity and higher phosphorous content for $\mathrm{TiO}_{2}$ films produced in a $\mathrm{H}_{3} \mathrm{PO}_{4}$ aqueous solution were achieved by first etching the Ti sample for 180 seconds in a HF solution, and then applying current densities in the 80 to $90 \mathrm{~mA} \cdot \mathrm{cm}^{-2}$ range for the micro-arc oxidation process.

\section{Acknowledgements}

The authors gratefully acknowledge the Brazilian science-funding agency $\mathrm{CNPq}$ for the financial support and grant to E. Peláez-Abellán, as well as for scholarships. The assistance in the roughness measurements by Prof. B. D'Giacomo, from the University of São Paulo (USP) at São Carlos, is also gratefully acknowledged. 


\section{References}

1. Dervos CT, Thirios EF, Novacovich J, Vassiliou P and Skafidas P. Permittivity properties of thermally treated $\mathrm{TiO}_{2}$. Materials Letters. 2004; 58:1502-1507. http://dx.doi.org/10.1016/j. matlet.2003.10.012

2. Han Y, Hong S-H and Xu K. Synthesis of nanocrystalline titania films by micro-arc oxidation. Materials Letters. 2002; 56:744-747. http://dx.doi.org/10.1016/S0167. $577 \mathrm{X}(02) 00606-7$

3. Oliveira NTC, Ferreira EA, Duarte LT, Biaggio SR, RochaFilho RC and Bocchi N. Corrosion resistance of anodic oxides onthe Ti-50Zr and Ti-13Nb-13Zr alloys. Electrochimica Acta. 2006; 51:2068-2075. http://dx.doi.org/10.1016/j. electacta.2005.07.015

4. Duarte LT, Biaggio SR, Rocha-Filho RC and Bocchi N. Influence of hydroxyapatite on the corrosion resistance of the Ti-13Nb-13Zr alloy. Journal of Materials Science: Materials in Medicine. 2009; 20:1009-1015. PMid:19083081. http://dx.doi. org/10.1007/s10856-008-3662-4

5. Van Drunen J, Zhao B and Jerkiewicz G. Corrosion behavior of surface-modified titanium in a simulated body fluid. Journal of Materials Science. 2011; 46:5931-5939. http://dx.doi. org/10.1007/s10853-011-5548-y

6. Okazumi T, Ueda K, Tajima K, Umetsu $\mathrm{N}$ and Narushima T. Anatase formation on titanium by two-step thermal oxidation. Journal of Materials Science. 2011; 46:2998-3005. http://dx.doi.org/10.1007/s10853-010-5177-x

7. Saji VS, Choe HC and Brantley WA. Nanotubular oxide layer formation on $\mathrm{Ti}-13 \mathrm{Nb}-13 \mathrm{Zr}$ alloy as a function of applied potential. Journal of Materials Science. 2009; 44:3975-3982. http://dx.doi.org/10.1007/s10853-009-3542-4

8. Yerokhin AL, Nie X, Leyland A, Matthews A and Dowey SJ. Plasma electrolysis for surface engineering. Surface and Coatings Technology. 1999; 122:73-93. http://dx.doi. org/10.1016/S0257-8972(99)00441-7

9. Yan Y, Han Y and Lu C.The effect of chemical treatment on apatite-forming ability of the macroporous zirconia films formed by micro-arc oxidation. Applied Surface Science. 2008; 254:4833-4839. http://dx.doi.org/10.1016/j. apsusc.2008.01.117

10. Yao Z, Jiang Y, Jia F, Jiang Z and Wang F.Growth characteristics of plasma electrolytic oxidation ceramic coatings on Ti-6Al4V alloy. Applied Surface Science. 2008; 254:4084-4091. http://dx.doi.org/10.1016/j.apsusc.2007.12.062

11. Ou KL, Shih YH, Huang CF, Chen CC and Liu CM. Preparation of bioactive amorphous-like titanium oxide layer on titanium by plasma oxidation treatment. Applied Surface Science. 2008; 255:2046-2051. http://dx.doi.org/10.1016/j. apsusc.2008.06.189

12. Duarte LT, Biaggio SR, Rocha-Filho RC and Bocchi N Preparation and characterization of biomimetically and electrochemically deposited hydroxy apatite coatings on microarcoxidized Ti-13Nb-13Zr. Journal of Materials Science: Materials in Medicine. 2011;22:1663-1670. PMid:21562888. http://dx.doi.org/10.1007/s10856-011-4338-z

13. Zha, Z, Che, X, ChenA, Huo G and Li H. Preparation of $\mathrm{K}_{2} \mathrm{Ti}_{6} \mathrm{O}_{13} / \mathrm{TiO}_{2}$ bio-ceramic on titanium substrate by micro-arc oxidation. Journal of Materials Science. 2009; 44:6310-6316. http://dx.doi.org/10.1007/s10853-009-3869-x

14. Sul Y-T, Johansson CB, Petronis S, Krozer A, Jeong Y and Wennerberg A. Characteristics of the surface oxides on turned and electrochemically oxidized pure titanium implants up to dielectric breakdown: the oxide thickness, micropore configurations, surface roughness, crystal structure and chemical composition. Biomaterials. 2002; 23:491-501. http://dx.doi.org/10.1016/S0142-9612(01)00131-4

15. Blackwood DJ and Peter LM. The influence of growth rate on the properties of anodic oxide films on titanium. Electrochimica Acta. 1989; 34:1505-1511. http://dx.doi.org/10.1016/00134686(89)87033-1

16. Sul Y-T, Johansson CB, Jeong Y and Albrektsson T. The electrochemical oxide growth behaviour on titanium in acid and alkaline electrolytes. Medical Engineering \& Physics. 2001; 23:329-346. http://dx.doi.org/10.1016/S1350 4533(01)00050-9

17. Marino CEB, Oliveira EM, Rocha-Filho RC and Biaggio SR On the stability of thin-anodic-oxide films of titanium in acid phosphoric media. Corrosion Science. 2001; 43:1465-1476. http://dx.doi.org/10.1016/S0010-938X(00)00162-1

18. Li L-H, Kong Y-M, Kim H-W, Kim Y-W, Kim H-E and Heo SJ Improved biological performance of Ti implants due to surface modification by micro-arc oxidation. Biomaterials. 2004; 25:2867-2875. PMid:14962565. http://dx.doi.org/10.1016/j. biomaterials.2003.09.048

19. Song W-H, Jun Y-K, Han Y and Hong S-H. Biomimetic apatite coatings on micro-arc oxidized titania. Biomaterials. 2004 25:3341-3349. PMid:15020106. http://dx.doi.org/10.1016/j. biomaterials.2003.09.103

20. Zhu X, Kim K-H and Jeong Y. Anodic oxide films containing $\mathrm{Ca}$ and $\mathrm{P}$ of titanium biomaterial. Biomaterials. 2001; 22:2199-2206. http://dx.doi.org/10.1016/S01429612(00)00394-X

21. Wei D, Zhou Y, Jia D and Wang Y. Characteristic and in vitro bioactivity of a microarc-oxidized $\mathrm{TiO}_{2}$-based coating after chemical treatment. Acta Biomaterialia. 2007; 3:817-827. PMid:17478133. http://dx.doi.org/10.1016/j. actbio.2007.03.001

22. Marino CEB, Nascente PAP, Biaggio SR, Rocha-Filho RC and Bocchi N. XPS characterization of an anodic titanium oxide films grown in phosphate buffer solutions. Thin Solid Films. 2004; 468:109-112. http://dx.doi.org/10.1016/j.tsf.2004.05.006

23. Matykina E, Doucet G, Monfort F, Berkani A, Skeldon $\mathrm{P}$ and Thompson GE. Destruction of coating material during spark anodizing of titanium. Electrochimica Acta. 2006; 51:4709-4715. http://dx.doi.org/10.1016/j. electacta.2006.01.021

24. Macdonald DD, Biaggio SR and Song H. Steady-state passive films. Interfacial kinetic effects and diagnostic criteria. Journal of the Electrochemical Society. 1992; 139:170-177. http:// dx.doi.org/10.1149/1.2069165

25. Jin F, Tong H, Shen L, Wang K and Chu PK. Micro-structural and dielectric properties of porous $\mathrm{TiO}_{2}$ films synthesized on titanium alloys by micro-arc discharge oxidization. Materials Chemistry and Physics. 2006; 100:31-33. http://dx.doi. org/10.1016/j.matchemphys.2005.12.001

26. Tang G-X, Zhang R-J, Yan Y-N and Zhu Z-X. Preparation of porous anatase titania film. Materials Letters. 2004;58:1857-1860. http://dx.doi.org/10.1016/j. matlet.2003.11.016

27. Ferreira EA, Oliveira NTC, Biaggio SR, Nascente PAP, Rocha-Filho RC and Bocchi N. XPS characterization of anodic oxides grown on biocompatible Ti-50Zr alloy in different acid electrolytes. Surface and Interface Analysis. 2006; 38:417-421. http://dx.doi.org/10.1002/sia.2271 